\title{
GRAĐENJE BRENDA I LOJALNOST
} KLIJENATA KAO ELEMENTI STRATEGIJE POSLOVANJA BANAKA

\author{
BUILDING BRAND AND CUSTOMER LOYALTY AS \\ ELEMENTS OF THE STRATEGY OF BANKS
}

\section{Pero Petrović}

Institut za međunarodnu politiku i privredu, Beograd, Srbija

\author{
Aleksandar Živković \\ Ekonomski fakultet Univerziteta u Beogradu, Beograd, Srbija
}

(C) MESTE NGO

JEL Category: G21, M31

\section{Apstrakt}

Savremeno bankarsko poslovanje zahteva nov kvalitet u pružanju bankarskih usluga, a to znači $i$ promene u kreiranju dobre slike o konkretnoj banci. Brend stvara nameru finansijskih institucija da upravljaju svojim korisnicima na način koji im obezbeđuje zadovoljstvo, dvosmernu komunikaciju i poverenje u razvoju lojalnosti. Nakon kreiranja kvalitetnog brenda, uključujući i razrešavanje različitih problema u tom procesu, posebna pažnja je usmerena na upravljanje brendom. Aktuelnost obezbeđivanja visokog nivoa zadovoljstva i lojalnosti klijenata je posebno izražena na bankarskom tržištu zbog intenzivne konkurencije i borbe za privrženost potrošača ali i sve većih zahteva klijenata. Ostvarenje stabilnog profita, u takvim uslovima, uslovljeno je strategijskim zaokretom banaka od obavljanja klasičnih transakcija $i$ intenzivne akvizicije novih potrošača ka zadržavanju postojećih $i$ građenjem dugoročnih odnosa sa njima. Kreiranje zadovoljstva i lojalnosti u takvim uslovima zahteva od banaka razvijanje poverenja i privrženosti i posmatranje klijenata kao partnera a ne samo kao korisnika vrednosti. Promene su uticale na usvajanje marketing orijentacije bankarskog sektora $i$ dvosmerne komunikacije ka korisniku. Upravo korisnik danas ima ključnu ulogu u procesu kreiranja brenda jer u odnosu na njegova očekivanja i percepciju usluge stvara se vrednost brenda ponude asortimana usluga i vrednost korporativnog brenda banaka. Neke od ovih promena su stvorile brojne

Adresa autora zaduženog za korespodenciju:

Pero Petrović

䤵pera@diplomacy.bg.ac.rs mogućnosti, dok su druge delovale ograničavajuće na ostvarivanje poslovnih ciljeva $i$ konkurentnost banaka. 
Ključne reči: građenje, brend, lojalnost, strategija, banka; marketing

\begin{abstract}
The modern banking requires a new quality in the provision of banking services, and that means a change in creating a good image of the particular bank. Brand is the need for financial institutions to manage its users in a way that provides them satisfaction, two-way communication and trust developing into loyalty was created. After creating a quality brand, including the resolution of problems in the process, special attention is focused on brand management. The significance of providing a high level satisfaction and loyalty is particularly visible in the commercial banking market, with intense competition, battle for clients and their devotion, but also constantly increasing client's demands. Maintaining stable profitability in such conditions is determined with strategic turn by commercial banks, from classic transactions and intense acquisition of new customers, towards retention of existing clients and building long-term relations with them. Creation of satisfaction and loyalty in the devotion and treating clients like partners and not just like value users. Changes influencing the adoption of marketing orientation of the banking sector and two-way communication to the user. Right now the user has a key role in the creation of the brand as compared to their expectations and perceptions of service creates brand value offers range of services and the value of the corporate brand banks. Some of these changes have created numerous opportunities, while others acted to constrain the realization of business objectives and competitive bank.
\end{abstract}

Keywords: building, brand, loyalty, strategy, banks;

\section{UVOD}

Kvalitet bankarskog poslovanja ima presudnu ulogu u građenju brenda bankarskih usluga, kao i lojalnosti klijenata, naročito imajući u vidu da banke posluju u okruženju koje se brzo menja. Bankarska usluga je, kao i svaka usluga, kompleksan i multidimenzionalan koncept. Sačinjava je suštinska usluga, koja označava konkretnu korist koja proizilazi iz korišćenja određene usluge. Ostale dimenzije usluge su: facilitatorske usluge koje omogućuju obavljanje transakcije (informisanje, naručivanje, obračun, plaćanje) i pojačavajuće usluge koje doprinose povećanju kvaliteta suštinske usluge (konsultacije, ljubaznost, sigurnost).

Nagle i intenzivne promene sve češće imaju karakter revolucionarnih a to od menadžmenta iziskuje adekvatno reagovanje. Uglavnom, tri osnovna faktora su uticala na obim i intenzitet promena na bankarskom tržištu: globalizacija tržišta, promene u ponašanju klijenata i razvoj novih tehnologija. Globalizacija tržišta i razvoj novih tehnologija su za posledicu imali: deregulaciju bankarskog tržišta, njegovu liberalizaciju, intenziviranje konkurencije, pojava novih bankarskih proizvoda, proces sekjuritizacije. Međutim, banke se suočavaju sa dinamičnim preferencijama i očekivanjima klijenata i njihovoj izraženoj diferenciranosti zasnovanoj na kupovnoj moći, stilu života i sistemu vrednosti. Lojalni klijenti važna su imovina svake banke i generatori profita jer regularno ponavljaju kupovine odnosno transakcije, osetljivi su na marketinške napore banke, obezbeđuju pozitivnu usmenu propagandu i duže se vezuju za banku. Satisfakcija klijenata je najvažnija determinanta lojalnosti, i pored toga što će jedan deo zadovoljnih klijenata, iz različitih razloga, preći na konkurentske marke.

\section{PROMENE NA SRPSKOM BANKARSKOM TRŽIŠTU}

$\mathrm{Na}$ srpskom finansijskom i bankarskom tržištu, posle 2000 godine, desile su se brojne promene koje su uticale na strukturu i konfiguraciju tog tržišta. Promene su uticale na usvajanje marketing orijentacije bankarskog sektora i dvosmerne komunikacije ka korisniku. Upravo korisnik danas ima ključnu ulogu u procesu kreiranja brenda jer u odnosu na njegova očekivanja i percepciju usluge stvara se vrednost brenda ponude asortimana usluga i vrednost korporativnog brenda banaka. Što se tiče metodologije istraživanja, važno je istaći da je glavna rasprava, u vezi sa osnovnim ciljem istraživanja, je utvrđivanje, poboljšanje, i bolje razumevanje glavnih problema koji se pojavljuju u procesu izgradnje brenda bankarskih usluga na finansijskom tržištu sa stanovišta 
korisnika. U tom kontekstu srpsko bankarsko tržište je reprezentativni primer novih tendencija i kretanja. Globalna konkurencija ostavila je manje prostora domaćoj, a zasićenje tražnje na nacionalnim tržištima i deregulacija učinili su srpsko tržište veoma atraktivnim za inostrane banke. Intenzivna konkurencija uslovila je kvalitetno novi način komuniciranja na tržištu, promenu postojećih poslovnih modela i strategija banaka, kontinuirano inoviranje portfolija poslova $i$ stalno uvođenje novih proizvoda prilagođenih potrebama i zahtevima klijenata. Bankarsko tržište, kao posledica toga, postaje fragmentisano, a klijenti sve zahtevniji. Stvaranje održive pozicije na tržištu zahteva od menadžmenta banke strategijski zaokret i usmeravanje na obezbeđenje totalne satisfakcije klijenata i povećanje stope ponovljenih kupovina odnosno transakcija. Sposobnost menadžmenta da ostvari te zahteve uslovljena je razvijanjem odnosa koji se zasnivaju na poverenju i lojalnosti klijenata prema konkretnoj banci i njenim proizvodima odnosno uslugama. Međutim, poslovna praksa ukazuje da je, i pored napora banaka da zadrže svoje vredne klijente, evidentna visoka godišnja stopa izgubljenih klijenata (Ćirović, 2007). Ovakva situacija uslovila je brojna teorijska i empirijska istraživanja koja su usmerena na identifikovanje determinanti satisfakcije i lojalnosti klijenata i sagledavanje njihove međusobne veze.

\section{PROBLEMI U PROCESU STVARANJA BRENDA}

Promene su uticale na usvajanje marketing orijentacije bankarskog sektora i dvosmerne komunikacije ka korisniku. Upravo korisnik danas ima ključnu ulogu u procesu kreiranja brenda jer u odnosu na njegova očekivanja i percepciju usluge stvara se vrednost brenda ponude asortimana usluga i vrednost korporativnog brenda banaka. Problemi u kreiranju brenda nastaju kao posledica pasivne i nediferencirane strategije komunikacije, nezadovoljstva korisnika kompletnom uslugom banke i nedostatkom poverenja između banke i korisnika.

Osnovna uloga promocije banaka je komunikacija prema ciljnim grupama (Kotler \& Keller, 2006). To pokazuje istraživanje na uzorku od 10 banaka koje posluju na teritoriji Beograda (Filipović, Vuković, Novičić, \& Daničić, 2010). Tabela 1 daje sliku o tome koliko je učešće prvih deset banaka $u$ pružanju usluga komitenata na uzorku od 1000 ispitanika.

Tabela br.1 Učešće banaka u pružanju usluga komitentima

\begin{tabular}{|l|l|}
\hline Banka INTESA & $24,7 \%$ \\
\hline Komercijalna banka Beograd & $20,6 \%$ \\
\hline Raiffeisenbank & $18,5 \%$ \\
\hline Poštanska štedionica & $17,1 \%$ \\
\hline Societe General & $8,2 \%$ \\
\hline Hypo alpe-adrria-bank & $6,0 \%$ \\
\hline EFC Eurobank & $5,5 \%$ \\
\hline HVB banka & $4,9 \%$ \\
\hline ProCredit BANK & $4,9 \%$ \\
\hline Alfa banka & 3,8 \\
\hline
\end{tabular}

Izvor: Filipović, V., Vuković, B., Novičić, B., \& Damjanović, V. (2010, str. 214).

Brending predstavlja proces kojim banke diferenciraju svoju ponudu od konkurencije (Jobber, 2004). Osobine banke koje isptanici iz uzorka preferiraju (u odgovorima je bilo moguće navesti više osobina), u strkturi osobina:
a. komunikativnost $79,3 \%$;
b. odgovornost $78,7 \%$;
c. savremenost $77,5 \%$;
d. ambicioznost $76,3 \%$;
e. inovativnost $65,7 \%$;
f. lojalnost $65,3 \%$;
g. interesantnost $52,2 \%$.

Većina ispitanika najviše veruje stranim bankama $(39 \%)$, dok u domaće banke ima poverenje $29,4 \%$, a ni u jednu ni u drugu poverenje nema $31,2 \%$ ispitanika. Pri tome se poverenje korisnika prema bankama razlikuje u odnosu na godine starosti.

Na veoma konkurentnom tržištu, kao što je srpsko tržište bankarskih proizvoda i usluga, skoro svakodnevno potencijalni korisnici su prosto „bombardovani“ različitim oblicima promocije. Zato, drugi glavni oblik promocije je ubeđivanje koje se, često, obavlja na netransparentan način. 
Poslovne banke, da bi zadovoljile zahteve svojih korisnika i izgradile snažan brend na tržištu, treba da na optimalan način kombinuju instrumente komunikacije i primenjuju koncept integrisane marketing komunikacije: sms poruke, e-mail poruke, web site, call centri, događaji i masovne komunikacije (TV, bilbord, novine, časopisi, publikacije, plakati i dr.). Na tržištu se može ponuditi veliki broj sličnih bankarskih usluga, najvažnije je biti drugačiji. Banke moraju da stvore takav bankarski proizvod ili uslugu koji su drugačiji od konkurencije, nešto zbog čega će korisnici bankama pokloniti svoje poverenje (Chernatony \& McDonald, 2008). Međutim, da bi banke u tome uspele moraju dobro poznavati želje i potrebe svojih korisnika. Izgrađivanje bilo kog brenda predstavlja dugotrajan i kompleksan proces. Prepoznatljivost $\mathrm{i}$ identitet brenda su vrlo bitni elementi ostvarivanja konkurentske prednosti banaka na tržištu. Ličnost brenda predstavlja ključni aspekt brend identiteta. Kreiranje ličnosti brenda sa kojim će se ciljna grupa identifikovati od suštinskog je značaja za odnos korisnika sa brendom. Ličnost brenda obezbeđuje jedinstvenu poziciju u mislima korisnika (Keller, 2008). Poverenje predstavlja važan elemenat koji utiče na kreiranje odnosa između korisnika i banke, odnosno stvaranje lojalnosti brendu. Napori u plasiranju promotivnih aktivnosti moraju se stimulisati i motivisati dovoljno da stvore interes i promovišu pozitivan stav korisnika prema bankama i izgradnju prepoznatljivog i kvalitetnog brenda konkretne banke.

Bankarski brend, posebno u odnosu na finansijske usluge, ima relevantnost prema korisnicima kad pomaže u potrazi za odabirom potencijalnih ponuda, posebno u odnosu dosta informacija pre korišćenja usluga kao što je slučaj sa mnogim finansijskim uslugama. Brend ustanovljava emotivni dogovor između banaka i korisnika što stvara osnovu za razvijanje odnosa. Ovo razvijanje odnosa je od najveće važnosti za finansijske usluge koje su tipično dugoročne, po prirodi i oslanjaju se na lojalnost komitenata $u$ dužem protoku vremena. Za banke je izuzetno važno poznavanje procesa izgradnje brenda koji se sastoji iz šest međuzavisnih faza (Petrović \& Živković, 2011):

1. preduslov za izgradnju brenda je da postoji kvalitetna ponuda usluga banke za korisnike;
2. izgradnja osnove brenda - vizija, misija brenda, diferencijacija na tržištu;

3. utvrđivanje dodatne vrednosti brenda ekstra servis, garancije;

4. dostizanje potencijala na tržištu - kada korisnici ne prihvataju supstitute;

5. održavanje vrednosti brenda korišćenjem instrumenata komunikacije da bi korisnici ponovo dolazili upravo u tu banku;

6. izgradnja lojalnosti brenda - stalni korisnici banke su lojalni i važni;

Promene koje se odnose na konkurentno okruženje, zakonske regulative i korišćenje savremene tehnologije u radu banaka kreirali su nove izazove sa kojima su se susreli menadžeri u bankarskom sektoru i potencirale važnost kreiranja i upravljanja brendom bankarskog proizvoda i usluga. Stvorena je potreba da bankarska industrija zadovoljava zahteve svojih potrošača na način koji im obezbeđuje zadovoljstvo, interaktivnu komunikaciju i poverenje odnosno lojalnost.

\section{UPRAVLJANJE BRENDOM}

U savremenim uslovima poslovanja na finansijskom tržištu osim neophodnosti kreiranja prepoznatljivog brenda potrebno je i njime efikasno upravljati. Osnovni cilj upravljanja brendom je da korisnici postanu svesni njegovog postojanja, da in zainteresuje i podstakne na korišćenje finansijski usluga, čime se ostvaruje dugoročna lojalnost korisnika prema brendu banke. Međutim, dok su korisnici finansijskih usluga glavni cilj promocije, postoji i izvestan broj drugih ciljnih grupa sa kojima banka želi da komunicira ili da im se predstavi. Oni obuhvataju, između ostalog, zaposlene, posrednike, akcionare i opštu javnost u zemlji. Rezultat toga je da su uloga promocije širi, od olakšane razmene sa korisnicima do informisanja i edukacije javnosti. Istraživanjem je ispitivan najpogodniji način komunikacije banke sa korisnicima i identifikovano je više oblika komunikacije sa korisnicima od koji su se izdvojila četiri glavna načina odnosno instrumenta komunikacije: (1) sms poruke (30,7\%); (2) e-mail $(29,4 \%)$; (3) televizija (28,5\%); (4) web site $(26,9 \%)$;

Prednost brendiranja u sektoru finansijskih usluga ogledaju se u identifikaciji ponude, kratko 
podsećanje na osobine ponude i koristi, razlikovanje ponuda slične vrste, smanjenje vremena potrage, povećanje ubeđenja korisnika, pomoć pri proceni kvaliteta i psihološka nagrada (Harrison, 2000). $\mathrm{Na}$ osnovu sprovedenog istraživanja i dobijenih rezultata ukazuje se da su korisnici svesni bitnih kriterijuma pri izboru brenda banke, pre svega, povoljnih uslova koji se odnose na visinu kamatnih stopa i rata pri uslovima korišćenja određenih bankarskih usluga, kvaliteta pruženih usluga, poverenja u rad banke, kao i u lokaciju banke. Stoga banka treba da uvek nastoji da udovolji željama svojih komitenata. To se, pre svega, postiže kontinuiranim istraživanjem zadovoljstva korisnika, praćenjem i analizom zahteva okruženja i tržišta, definisanjem ponuda koje će imati dodatnu vrednost $\mathrm{i}$ biti jedinstvene za komitente. Nasuprot ovome, korisnik će biti nezadovoljan što će ga navesti na korišćenje nekog drugog, dobro pozicioniranog i prepoznatljivog brenda. Međutim, pored praćenja korisnika i njihovih zahteva za kvalitetan brend banke je bitno i da prati način rada ostalih konkurenata na bankarskom tržištu. Na taj način može se doći do saznanja šta je to novo i drugačije što mogu da ponude klijentu u odnosu na ostale prisutne brendove banaka, što će korisnik, svakako, umeti da prepozna, kao dobar atribut tog brenda. To je način sticanja obostranog zadovoljstva i efikasne saradnje u poslovanju. Naročitu pažnju treba posvetiti dvosmernoj komunikaciji koja se uspostavlja između klijenta i banke, odnosno obrnuto. Potrebno je usaglasiti sve instrumente komunikacije kako bi se ostvario pozitivan imidž i visoka vrednost brenda banke. To znači primenjivati diferenciranu strategiju komuniciranja prema različitim tipovima klijenata. Međutim da bi izgradila poverenje prema korisnicima banka treba da uvek plasira tačnu, relevantnu, razumljivu i blagovremenu informaciju i pruži finansijski savet da bi pomogla korisniku da bolje razume poslovanje banke i uslove koje mu ona može pružiti uz plasman svojih usluga. Pri tome je važno da percepcija pružene usluge premaši očekivanja korisnika, što se odnosi na unapređenje poslovanja banaka: više inovacija, interesantnih sadržaja za korisnike i veći stepen uzajamnog poverenja.

\section{FAKTORI LOJALNOSTI KLIJENATA BANKE}

U savremenim uslovima poslovanja banaka jedan od najvažnijih zadataka menadžmenta je satisfakcija potrošača i njihovo dugoročno zadržavanje. Primat zadržavanja postojećih u odnosu na osvajanje novih klijenata uslovljen je, pre svega, intezivnim konkurentskim pritiscima $i$ visokim troškovima osvajanja novih. Najefikasniji način zadržavanja potrošača je građenje lojalnosti klijenata kontinuiranim obezbeđivanjem satisfakcije i stvaranjem visokih troškova prelaza na druge marke. Postoje izvesne studije koje ukazuju da se kvalitet isporučene usluge smatra ključnom determinantom ostvarenog nivoa satisfakcije klijenata svake uslužne organizacije (Pollack, 2008). S druge strane, međutim, postoje $i$ istraživanja koja nisu pokazala visoku korelaciju kvaliteta usluga i zadovoljstva potrošača (Lovreta, Berman, Petković, Veljković, \& Crnković, 2010). To znači da kvalitet isporučene usluge nije jedina determinanta satisfakcije klijenata, kao i da satisfakcija klijenata nije jedina determinanta njihove lojalnosti. Zbog toga su napori uslužnih organizacija usmerene na stvaranje vrednosti koja je veća od vrednosti konkurenata u cilju obezbeđenja totalne satisfakcije klijenata. Jedino totalna satisfakcija na svim tačkama kontakta sa klijentom vodi njihovoj dugoročnoj lojalnosti i zadržavanju (Đukić \& Stojković, 2013). Ukupno zadovoljstvo klijenata je generisano kvalitetom rezultata uslužnog kontakta, kvalitetom uspostavljene interakcije i kvalitetom uslužnog okruženja. Kvalitet rezultata predstavlja stvarni rezultat uslužnog kontakta i osnovni je elemenat kvaliteta jedne usluge, s obzirom na to da odlukom o kupovini klijent procenjuje konkretnu korist koja se očekuje od njenog korišćenja. Kvalitet interakcije odnosi se na procenu ukupnog odnosa klijenta i uslužnog osoblja iz koga dolazi do pretvaranja inputa u rezultat. Kvalitet uslužnog ambijenta je treća dimenzija usluge koja pruža vizuelne podsticaje $u$ organizaciji, njenom funkcionisanju i uslugama (objekti, oprema, enterijer).

Poverenje i privrženost su najvažnije determinante lojalnosti klijenata banke. I dok će odsustvo poverenja, najverovatnije, značiti gubitak partnera, sa druge strane pozitivne performanse partnera, posebno kvalitet 
isporučene vrednosti doprinose jačanju poverenja. Dugoročno poverenje između banke i klijenata stvara privrženost. Privrženost je, pored poverenja, ključni faktor $u$ formiranju jednog kvalitetnog odnosa. Privrženost potrošača nastaje kao rezultat opažene razlike između troškova i koristi (ekonomskih, društvenih, statusnih). Ona doprinosi kreiranju imovine koja nije vidljiva tj. materijalna, ali je veoma vredna. Postoje dve vrste privrženosti-afektivna (osećajna) , koja je autentična i zasniva se na pozitivnim osećanjima prema partneru i istinskoj naklonosti. Proračunata privrženost je rezultat nedostatka alternativa - bolje ostati sa nekim, dok se ne pojavi bolja prilika, odnosno partner koji će doneti veću korist. Ove dve dimenzije u korelaciji daju sinergetski efekat koji za krajnji ishod ima postizanje satisfakcije i u optimalnoj varijanti i dugoročnu lojalnost klijenata (Đukić \& Stojković, 2013).

\section{IZBOR STRATEGIJE BANKE}

Sposobnost banke da ostvari visoku stopu lojalnosti klijenata sve više je uslovljena primenom principa relacionog marketinga. $U$ pitanju je Relationship banking, pristup u čijem je fokusu građenje i održavanje međuzavisnih korisnih odnosa banke sa visoko vrednim klijentima. Ovaj pristup ima za cilj obezbeđenje stabilnog profita kroz ostvarivanje lojalnosti visoko vrednih klijenata. Napori banaka su, stoga, usmereni na pojedinačne profitabilne klijente sa kojima razvijaju dugoročne odnose $\mathrm{i}$ različite nivoe međuzavisnosti. Primena relacionog marketinga u bankama zasniva se na sledećim varijablama (Đukić \& Stojković, 2013):

- Poverenje, predstavlja verovanje u integritet partnera i istinitost njegovih reči i obećanja i u skladu sa tim spremnost učesnika međuzavisnih odnosa da se u procesu kreiranja i razmene vrednosti osloni na drugu uključenu stranu;

- Obavezivanje, predstavlja garanciju druge strane uključene u odnose da će raditi na razvijanju uzajamno korisnih odnosa, to jest da će korist od formiranja odnosa imati obe strane koje in formiraju i neguju;

- Privrženost, se može objasniti kao razvijanje uzajamnih zavisnosti, koja je vođena željom da se razvijaju stabilni odnosi i spremnost da se žrtvuju kratkoročni interesi u korist vrednosti koju će doneti dugoročni odnosi;

- Empatija, je sposobnost partnera da probleme posmatra iz ugla druge strane i ona predstavlja dimenziju kod koje je emotivni aspekt posebno naglašen, ne samo $u$ poslovnom, već i u svakom međuljudskom odnosu;

- Reciprocitet, podrazumeva odgovarajuća uzimanja i davanja na kojima su učesnici u međuzavisnom odnosu i ustupke koji čine jedni drugima, što jača snagu partnerskih odnosa i povećava poverenje i privrženost;

Međutim, poverenje je ključna dimenzija međuzavisnih odnosa sa klijentima na kojoj se zasniva stvaranje svih ostalih dimenzija odnosa. Dakle, poverenje je spremnost učesnika međuzavisnih odnosa da se u procesu razmene vrednost osloni na partnera (Morgan \& Hunt, 1994). Poverenje postoji kada uključene strane veruju u integritet i pouzdanost svojih partnera. Zbog toga je poverenje ključan faktor u procesu razvijanja odnosa sa klijentima, bez čijeg postojanja nije moguće ostvariti kvalitetan i dugoročno koristan odnos. Konflikti koji mogu da nastanu u odnosima će se uspešnije prevazići ako postoji poverenje, a svaka konfliktna situacija koja se reši u korist svih uključenih strana, dodatno će pojačati privrženost partnera u razmeni. Ukupna poslovna strategija banke mora biti usklađena sa svim ciljevima poslovanja i treba da bude integralni deo korporativnog ili strategijskog plana. Pri formulisanju strategije postoje tri osnovne faze (Petrović \& Živković, 2011):

1. odabiranje ciljnog tržišta / odabir preferencijalnih klijenata,

- zasniva se na nekoliko faktora:

- usluzi koja se nudi,

- pristupačnost tržišnog segmenta,

- održivosti različitih tržišta;

2. razvoj generalne ideje o vrsti ponude za željeno tržište u odnosu na konkurentske ponude, tj. alokacija resursa;

3. alociranje marketing resursa;

Pre nego što identifikuje ili razvije konkurentsku prednost, banka najpre mora da uspostavi granice tržišta ili grupe tržišta na kojima ona konkuriše. U praksi, pri tome, može da koristi tri glavna 
pristupa: mere elastičnosti, kretanje relativnih cena i pregledi industrije i potrošača.

Međutim, treba imati u vidu da se finansijske usluge karakterišu visokim stepenom informacione asimetrije između kupaca i prodavaca, sa potrošačima koji šesto ne poseduju podrobna specijalistička znanja (Davlin \& Ennew, 1997) . Neopipljivost finansijske usluge predstavlja osnovni razlog na kome se zasniva problem asimetričnih informacija i oslanjanje potrošača na kvalitet, koji se odnosi na iskustvo i poverenje. Konkurentska strategija se bavi kreiranjem i održavanjem konkurentske prednosti iznad rivala. U nastojanju da ostvari konkurentsku prednost (atraktivnu poziciju) banka, mora biti sposobna da izvrši neophodne diskretne aktivnosti (lanac vrednosti) na uspešniji i efikasniji način od svojih konkurenata. Strategija redizajniranja banke počinje identifikovanjem tri različite grupe usluga koje banka treba da ponudi (Meiden, 1996):

1. Neposredne usluge koje ne zahtevaju personalnu uslugu ili savet (prenos novca, izvod sa računa);

2. Brze usluge koje zahtevaju mere personalnog vođenja od strane bankarskog osoblja (pitanja u vezi kreditnih kartica, mali zajmovi, otvaranje računa);

3. Usluge koje zahtevaju savete eksperata i smišljeno vođenje od strane osoblja (zalaganje kuća, osiguranje, upravljanje imovinom);

Tri kritična faktora uspeha na konkurentskom tržištu, u bankarskoj industriji su (Johanson, F., Johanson, D., 1985): širina i dubina proizvodne i uslužne linije, niski operativni troškovi i dobra bankarska reputacija. Zatim, banke se moraju suočiti sa takvim snagama, kao što su deregulacija i povećana konkurencija. S druge strane koncepti lanca vrednosti i konfiguracije banke trebaju biti upotrebljeni za razvijanje konkurentske prednosti banke, u tom smislu su identifikovana četiri izvora konkurentske prednosti banke (Canals, 1993): zaposleni, finansijski menadžment, imovinska osnova, neopipljiva imovina; Primeri marketinških ciljeva čijim ostvarenju može da teži poslovna banka u pojedinim fazama svog razvoja mogu biti (Komazec, Živković, \& Ristić, 2000):
- povećanje dobiti (profita) banke,

- povećanje tržišnog učešća,

- investiranje u rast i razvoj banke,

- povećanje kvantuma depozita banke,

- racionalizacija kreditnih plasmana,

- podizanje sveukupnog imidža banke,

- međunarodna ekspanzija banke,

- ekspanzija asortimana bankarskih proizvoda i usluga,

- proširenje mreže poslovnih jedinica,

- izgradnja novih profitnih centara banke u odnosu na konkurenciju;

Imajući u vidu finansijske krize i promene $u$ ukupnoj strukturi finansijskog tržišta kao i aktuelnu poslovnu strategiju konkretne poslovne banke, potrebno je doneti stratešku odluku u pogledu osnovnih pravaca poslovanja banaka u budućnosti. Pri tome banka nastoji da usmeri svoje poslovanje u profitabilnije pravce $\mathrm{i}$ da se povlači iz manje profitabilnih. Drugim rečima, to je opredeljenje da li banka želi da proširi geografsko područje svoga delovanja (otvaranjem novih filijala, akvizicijom ili prodorom na novo geografsko područje), u kojoj meri želi da poveća svoj bilansni nivo (u pogledu depozita, veličine bilansne sume) i koliki stepen diversifikacije finansijskih proizvoda želi da ponudi $u$ nastupajućem periodu.

Imajući u vidu finansijske krize i promene $u$ ukupnoj strukturi finansijskog tržišta kao i aktuelnu poslovnu strategiju konkretne poslovne banke, potrebno je doneti stratešku odluku u pogledu osnovnih pravaca poslovanja banaka u budućnosti. Pri tome banka nastoji da usmeri svoje poslovanje u profitabilnije pravce $\mathrm{i}$ da se povlači iz manje profitabilnih. Drugim rečima, to je opredeljenje da li banka želi da proširi geografsko područje svoga delovanja (otvaranjem novih filijala, akvizicijom ili prodorom na novo geografsko područje), u kojoj meri želi da poveća svoj bilansni nivo (u pogledu depozita, veličine bilansne sume) i koliki stepen diversifikacije finansijskih proizvoda želi da ponudi u budućem periodu. 


\section{ZAKLJUČAK}

Nagle promene na bankarskom tržištu i izbirljivost klijenata i raznovrsnost izbora utiču na stalno povećavanje nivoa očekivanja $u$ narednim kupovinama odnosno transakcijama. Savremen koncept upravljanja brendom fokusiran je na istraživanje stavova i ponašanja korisnika, na planiranje integrisane marketing komunikacije, realizaciju komunikacije i evaluaciju postignutih rezultata. S druge strane, lojalnost klijenata predstavlja osnov konkurentnosti poslovnih banaka.

Predmet ovog rada usmeren je na analizu korporativnog brenda banaka, međuzavisnost između brenda porekla banke i kriterijuma izbora bankarskih usluga, kao i adekvatnih instrumenata komunikacije prema korisnicima usluga. Za analizu je korišćen uzorak od 1000 komitenata na teritoriji Beograda. Cilj istraživanja nije tretman osnovnih bankarskih proizvoda (kredit, štednja, platne kartice) ili komparacije banaka u ostvarivanju finansijskih pokazatelja uspešnosti poslovanja, nego da prikaže poslovne banke kao "ličnosti“ brenda, određene starosti i osobina, ističući emotivnu komponentu brenda kod korisnika usluga. To može pomoći menadžerima da uspešnije kreiraju korporativni brend u skladu sa željama korisnika odnosno komitenata banke.

Istraživanje procesa kreiranja brenda dovelo je do sledećih zaključaka:

a. veoma je važno da je klijent uključen u proces kreiranja brenda;

\section{CITIRANI RADOVI}

Canals, J. (1993) Competitive strategies in European Banking. Marketing Management, 2(2), 26.

Chernatony, L., \& McDonald, M. (2008). Creating Powerful Brands in Consumer, Service and Industrial Markets. Elsevier, Butterworth Heinemann, p.32.

Ćirović, M. (2007). Finansijska tržišta: instrumenti, institucije, tehnologije. Beograd: Naučno društvo Srbije, 197-218.

Filipović, V., Vuković, B., Novičić, B., \& Damjanović, V. (2010). Proces građenja brenda bankarskih usluga. Marketing, 4, Beograd, p. 2006.

Davlin, J. \& Ennew,T.C. (1997). Understanding competitive advantage in retail financial service, International Journal of Bank, 15(3), 73-82.

Đukić, S., \& Stojković,A. (2013). Lojalnost klijenata kao osnova konkurentnosti poslovnih banaka, 16th b. uvažavanjem kriterijuma na osnovu kojih se adekvatne strategije komunikacije prema ciljnoj grupi, i

posledica pasivne i nediferencirane strategije komunikacije, nezadovoljstva korisnika kompletnom uslugom banke i nedostatkom poverenja između banke i korisnika.

Uspešan brend banke kreira se na način što korisnici bankarskih proizvoda i usluga izgrađuju dugoročne odnose sa bankom koji se zasnivaju na poverenju, emotivnom doživljaju i uzajamnom razumevanju.

U sagledavanju odnosa satisfakcije i lojalnosti klijenata treba imati u vidu da se informacije koje se dobijaju u procesu merenja satisfakcije odnose na određeni momenat. $S$ druge strane, emocionalan odgovor klijent nakon obavljene kupovine menja vremenom pod uticajem brojnih faktora. U slučajevima korišćenja bankarskih vremenskog ciklusa korišćenja određene usluge, kao što je, na primer, korišćenje dugoročnog kredita. Osnovna pretpostavka razvijanja uspešnih dugoročnih odnosa je da različitim klijentima treba razvijati odgovarajući nivo i tip odnosa, polazeći od njihove vrednosti za banku i značaja banke za njih. Samo ovakav pristup u formiranju dugoročno korisnih odnosa sa klijentima može banci doneti konkurentsku prednost na zasićenom bankarskom tržištu. klijenti odlučuju za banku, kreiraju se usluga osećaj satisfakcije je varijabilan i zavisi od

\footnotetext{
International Conference: Depandability and Quality management ICDQM-2013, Belgrade. 124-129.
} 
Harrison, T. (2000). Financial Service Marketing, London: Harlow, Pearson Education Limited.

Johnson, F.P. \& Johnson, R.D. (1985). Commercial Bank Management, Dow Jones-Irwin, Homewood,II.

Komazec, S., Živković, A., \& Ristić, Ž. (2000), Poslovna politika banaka, Beograd: Ekonomski fakultet. 22.

Kotler, P., \& Keller, K. (2006). Marketing menadžment, Beograd: Data status.

Lovreta, S., Berman, B., Petković, G., Veljković, S., Crnković, J., \& Bogetić,Ž. (2010). Menadžment odnosa sa kupcima. Beograd: Data status.

Meiden, A. (1996). Marketing financial Services, Mac Millan.

Morgan, R.M., \& Hunt Sh.D. (1994). The Commitment-Trust Theory of Relationship Marketing. Journal of Marketing, 58. 20-38.

Petrović, P., \& Živković, A. (2011). Marketing u bankarskoj industriji. Beograd: Čigoja štampa.

Pollack, B.L. (2008). The nature of the Service Quality and Satisfaction Relationship, Emperical Evidence for the Existence of Satifiers and Dissatisfiers. Managing Services Quality, 18(6), 537-558.

Datum prve prijave: $\quad$ 02.04.2014.

Datum prijema korigovanog članka: 26.03 .2015$.

Datum prihvatanja članka: 21.06.2015.

\section{Kako citirati ovaj rad? / How to cite this article?}

Style - APA Sixth Edition:

Petrović, P., \& Živković, A. (2015, jul 15). Građenje brenda i lojalnost klijenata kao elementi strategije poslovanja banaka. (Z. Čekerevac, Ed.) FBIM Transactions, 3(2), 97-105. doi:10.12709/fbim.03.03.02.12

Style - Chicago Sixteenth Edition:

Petrović, Pero, and Aleksandar Živković. 2015. "Građenje brenda i lojalnost klijenata kao elementi strategije poslovanja banaka." Edited by Zoran Čekerevac. FBIM Transactions (MESTE) 3 (2): 97-105. doi:10.12709/fbim.03.03.02.12.

Style - GOST Name Sort:

Petrović Pero and Živković Aleksandar Građenje brenda i lojalnost klijenata kao elementi strategije poslovanja banaka [Journal] // FBIM Transactions / ed. Čekerevac Zoran. - Beograd : MESTE, jul 15, 2015. - 2 : Vol. 3. - pp. 97-105.

\section{Style - Harvard Anglia:}

Petrović, P. \& Živković, A., 2015. Građenje brenda i lojalnost klijenata kao elementi strategije poslovanja banaka. FBIM Transactions, 15 jul, 3(2), pp. 97-105.

Style - ISO 690 Numerical Reference:

Građenje brenda i lojalnost klijenata kao elementi strategije poslovanja banaka. Petrović, Pero and Živković, Aleksandar. [ed.] Zoran Čekerevac. 2, Beograd : MESTE, jul 15, 2015, FBIM Transactions, Vol. 3, pp. 97-105. 